\title{
PUBLIC SPACES AND PRIVATE CONFLICTS IN THE NEW URBAN AGENDA
}

\author{
MICHAEL W. MEHAFFY, PETER ELMLUND \& TIGRAN HAAS \\ Centre for the Future of Places, KTH Royal Institute of Technology, Sweden
}

ABSTRACT

The New Urban Agenda, developed at the UN-Habitat III conference on sustainable urban development and later adopted by consensus by 193 countries, includes nine paragraphs affirming the importance of robust public space networks for sustainable and functional cities. But what are the essential requirements for functional public space in cities? What are the current challenges and shortcomings - especially at a time of rapid urbanization, and the decline of public spaces in many cities? We report on a literature survey done by the Centre for the Future of Places at KTH Royal Institute of Technology, as part of a collaboration with UN-Habitat towards implementation of the New Urban Agenda. The literature provides ample evidence that public spaces are arenas for numerous potential conflicts, but also, if properly allocated and structured, places of peaceful copresence, creative interaction, participation, and co-production. Furthermore, a critical aspect of successful public space is the ability to self-organise into a structure of territorial regions, combining private interiors with connective public edges. We discuss larger lessons for city structure, design and development strategy, and sustainable urbanisation for the future.

Keywords: New Urban Agenda, public space, co-presence, co-production.

\section{INTRODUCTION}

It is only recently, with the emergence of new research, that we have begun to understand just how important public space systems are for city functioning. In particular, we are learning how public spaces serve as essential city-wide connective networks at many scales, through key structural characteristics. Along with that understanding has come a clearer picture of the intimate connection between the public aspects of urban space, and the more private aspects - not only the fully private built spaces that often line public spaces, but also the more subtle and complex tissue of regions within and adjacent to public spaces, transitioning from the most public realms into the more private ones. We now see that public space is far from one undifferentiated thing, but has its own complex structure of regions, adjacencies, formal and tacit rules, and dynamic evolution. We can understand that public space is a complex mix of public life and private life, or if you like, private lives with important lessons for policy and design.

The research on public space has begun to give us a much clearer picture of these benefits and how they work. In the process, the research has provided helpful evidence to influence and guide policymakers and designers - to help to answer the questions, "why should I care about creating and maintaining better quality public spaces?" "How can I actually do this, in a way that is feasible, economically viable, and maximally beneficial?"

These turns out to be urgent questions at the current moment in history, when many cities around the world are urbanizing at historically unprecedented rates. We see evidence that the degree to which these cities urbanize on the frameworks of good quality public space will determine their future capacity to generate human benefits and limit human dysfunctions, even catastrophes.

Reflecting this growing awareness, the United Nations' 2016 "Habitat III" conference incorporated significant language about the importance of public space in its "New Urban Agenda" outcome document, meant to guide urbanization policy for the next two decades. 
That document has been adopted by acclamation by all 193 member countries of the United Nations, elevating the topic of public space to new prominence. Now the focus is on implementation, and there is an urgent need for useful research on public space to guide evidence-based implementation.

\section{SURVEYING THE EXISTING LITERATURE}

One of the chief problems with the research on public space to date is that it has existed for the most part in fragmentary form within separate disciplines, lacking the unified picture needed to guide policy and design. Instead, knowledge is fragmented and each discipline has an incomplete picture. The problem is a little like the proverb of the elephant and the blind men, each of whom encounters a different part of the elephant: one of them finds a tree trunk, one finds a snake, another a leaf and so on - but none of them finds the elephant.

Two hopeful trends have arisen to correct this problem. One is that an inter-disciplinary "science of cities" has emerged, investigating over-arching structural properties of cities, and discovering that public space networks are central components. Another is that interdisciplinary centres have arisen to survey the research and to "connect the dots" between the literature in different fields, drawing overarching conclusions for policy and practice. One of these is the Centre for the Future of Places in Stockholm. The Centre's "Public Space Database Project" has assembled a coded database of existing research literature, using it to draw out key concepts and conclusions from the literature, and to write a series of policy and design guidance documents, in partnership with UN-Habitat and other partners. In turn, where gaps are identified in the literature, new research can be commissioned, often drawing from project-based field research aimed at implementing the New Urban Agenda.

The research at the Centre for the Future of Places has clarified the picture of public space as a complex network of territories and governance rules, both tacit and explicit. In this connection, of note is the work of Madanipour [1], who describes the territories of control that form within public spaces, often functioning as quasi-private spaces with tacit rules of control.

For example, if a person spreads out a picnic blanket in a park, and a stranger accidentally step on a corner of it as they walk by, the person is not likely to be too bothered. On the other hand, if the stranger perches on the blanket, it will likely be evident to both people that the stranger has broken some tacit rule about the blanket owner's control of that space - even though, properly speaking, they are both in public space, which they both have the right to occupy.

Another similar example is a cafe seating area in the streetscape, which is typically licensed by the City to the cafe. Nonetheless it is occupying public space, and if a person happens to pass by and see a friend at a table, they might perch there for just a few moments to say hello. But if they linger for too long, a waiter from the cafe is likely to ask insistently if they would like to order. If not, the waiter may then invite them to leave. Yet this table is in the public right of way of the street. The waiter is not the owner of the space - and not even the owner of the adjacent restaurant!

These and many other examples remind us that public space often has, so to speak, its own private lives, and its own complex set of regions with tacit and formal rules shaping many layers of private life. The picture becomes even more complex when we look at the larger network extending into truly private and transitional spaces, with all their complexities - as we will consider in more detail below. 


\section{TEASING OUT THE VARIABLE "PUBLICNESS" OF PUBLIC SPACE}

As the examples above suggest, we can see that public space is far from one undifferentiated "public" zone. Rather, each local space is a component of a wider network of public and private spaces, and the structures we create (sometimes only temporarily) to delineate these spaces. As we delineate them, we separate them from one another, while still preserving connections between them - connections that, as we will see, can often be adjusted over time.

This series of spaces, starting with the most public and ending with the most private and enclosed buildings, is really of the essence of cities. When we get this wrong - when we fail to delineate these spaces carefully, with adequate public space - we create enormous problems. As Joan Clos, Secretary-General of the Habitat III conference put it:

In general, the urban community has become lost in strategic planning, masterplanning, zoning and landscaping ... All these have their own purposes, of course - but they don't address the principal question, which is the relationship in a city between public space and buildable space. This is the art and science of building cities - and until we recover this basic knowledge, we will continue to make huge mistakes [2].

Why have we lost the "basic knowledge" about the relation of public space to buildable and private space, as Clos says? Broadly speaking, we have somehow failed to understand what cities actually are. They are, in an important sense, marvellous structures that mediate between conflicting freedoms. We need to explore a bit more what that means.

\section{PUBLIC SPACES AND PRIVATE LIVES: FREEDOM AND CONFLICT}

Cities (a broad term under which we also include towns) pose an intriguing paradox. On the one hand, they open up new freedoms to us to expand our life choices, to become more productive and more prosperous, and to enjoy the city, its resources and its cultural treasures. At the same time, cities bring us into conflict with others - conflicts over adjacencies, over noises and smells, over competition for space in crowded places, and other disruptions. These problems pose limitations on our freedom to enjoy the life of the city. We cannot occupy or move through a given space, say (because someone has put up a wall, for example) or be free from noise (because we live next to a noisy neighbour), or access the resources that cities offer us (because we are too isolated).

But something marvellous has happened in cities over time. In the best cities, we have gradually evolved structures that have mediated between these conflicting freedoms - that have provided both connectivity and separation, freedom and organization. One could say that these mediating structures are of the essence of urbanism.

A simple example can illustrate how these mediating structures work, and how public space plays a central role.

Imagine that we live in one dwelling, and a neighbour lives in another dwelling adjacent to you. The neighbour would like the freedom to party until 3:00 am, while we would like the freedom to sleep soundly without being awakened by their noise! Each of us seeks a form of freedom, but finds our freedoms in conflict (Fig. 1(a)).

One way to resolve this conflict is simply to separate our two homes by such a distance that we are no longer disturbed by their noise (Fig. 1(b)). We live over here, they live over there, and with enough separation, voila - problem solved. They may party happily into the night, while we may sleep soundly. 


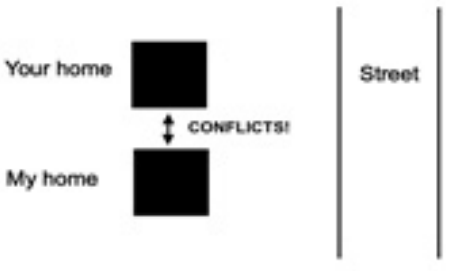

(a)

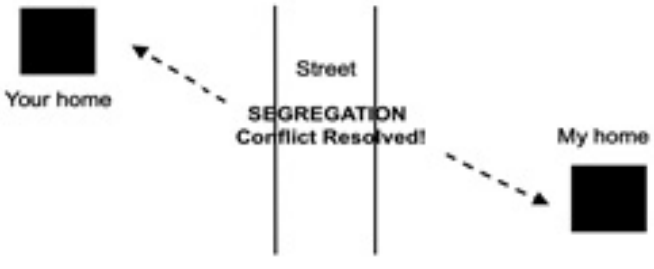

(b)

Figure 1: A simple method to resolve urban conflicts: spatial segregation.

But there is another crucially important way to mediate between our conflicting freedoms. Imagine that instead of simply segregating our homes, we create structures that control our privacy, our noise and smells, and our other areas of potential conflict. We agree to erect, let us say, a wall between our two homes, with sound insulating qualities.

Now we are separated from one another, in a way - but we are not segregated. Indeed, we are still connected in a powerful, mediated way - namely, through the systems of private and public spaces that connect our two homes. Our own bedroom, the most private part of our home, is connected to our living room, and to our front entry, perhaps to a porch or semi-private outdoor zone, where visitors (including our neighbours) may enter - but it is understood that they may not linger, as they are guests on our property. Then that space is in turn connected to the public zones of the street - and over to their house, where a similarly complex set of zones transitions to their most private spaces (Fig. 2).

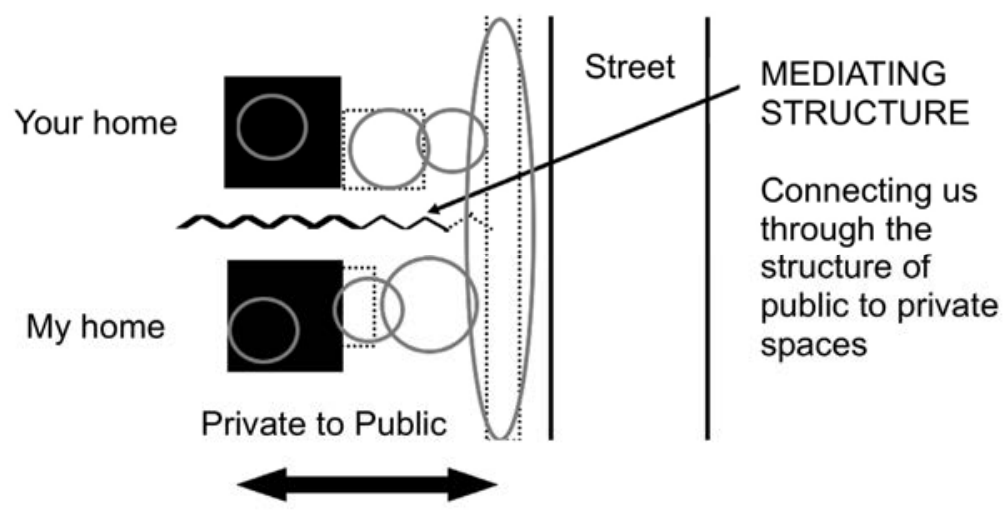

Figure 2: Another method to resolve urban conflicts, through mediating structures.

In this way, we are intimately connected to each other through public space, yet we are able to control the conflicts that might restrict our freedom and our privacy. In our house, we can close a door or window, draw a curtain, lock our doors - or conversely, we can open those things, and welcome our neighbours in. In fact we can operate a dizzyingly complex network of connections, as can they - connections between spaces that have a membranelike capacity to let some things through (sounds, sights, people, etc.) and exclude others, at different times and to different degrees. 


\section{UNDERSTANDING THE COMPLEXITY OF PUBLIC SPACE AND "PLACE NETWORKS"}

Nor do these networks of room-like places - we will hereafter call them "place networks" stop with built private structures and their literal rooms. Outside of private homes and commercial establishments, one can often observe a dizzyingly complex series of room-like spaces, also defined spatially with structural elements or demarcating devices, and often containing clear points of connection to adjacent spaces. These structures may take the form of yards, forecourts, porches, platforms, sidewalk or pavement zones, or other structures. They may even be quite informal - like the picnic blanket discussed earlier.

An example can be seen in the montage image (Fig. 3), a rather ordinary section of a typical London "high street" - which, as it happens, was around the corner from where one of the authors once lived. It is possible to see many different room-like places where people can be, from the most private spaces, including literal rooms like bedrooms, to the most public spaces along the street, which often have only partially defined room-like spaces such as the outdoor seating area next to the restaurant. Between these two extremes is a remarkably complex tissue of spaces, with mediating structures between them - where one can move, but not if a door is closed, or see, but not if a window blind is drawn, or a hedge obscures the view. Or one can hear, but not if there is glass in the window, and so on. The entire network is an intricate web of spaces and connections, and the diagrammatic lines and circles shown here only hint at its complexity.

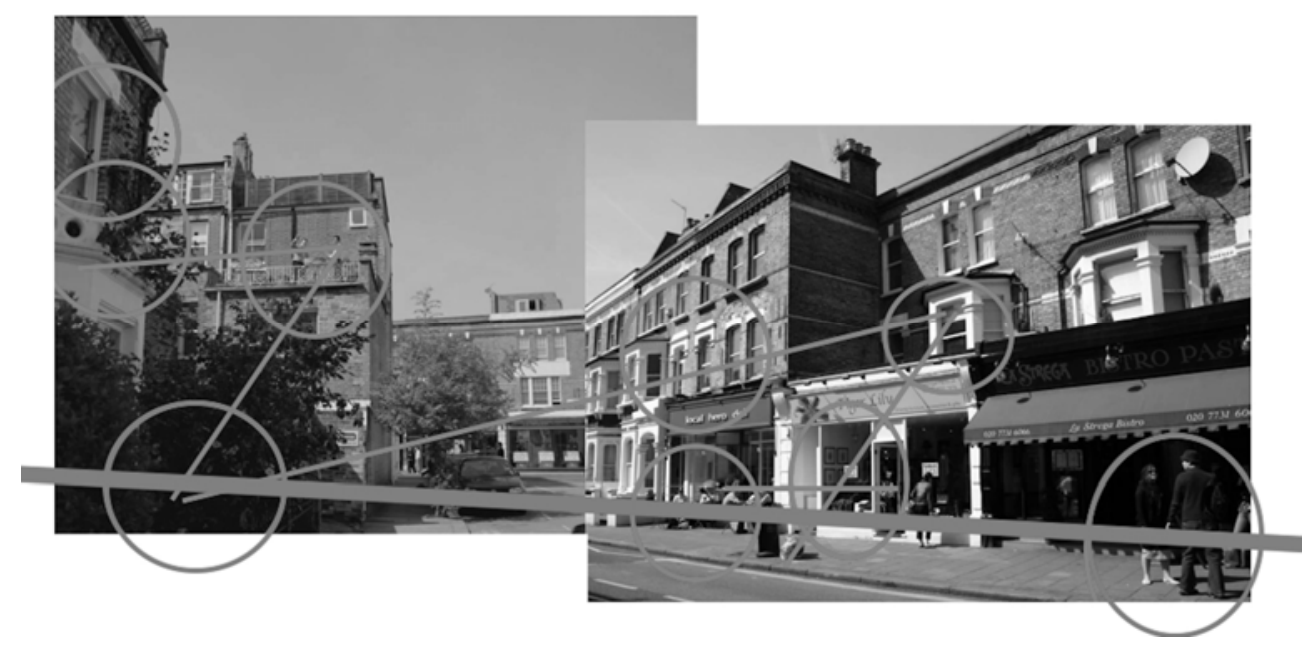

Figure 3: The spaces that can be occupied on an ordinary London street form a dizzying network of connections, from the most private to the most public, and including connections of movement, sight, and sound.

Once again, an important point is that we, the users, can modulate the connections between these places and their place networks. We can open doors, close windows, draw blinds, and so on. We can choose our level of public exposure, from a lively place on the street or the square, to the most secluded and quiet place in a bedroom, and many places in between. This capacity for adaptation to varying need (at different times, between different people, etc.) is an important feature. 
Not only can these changes happen at small scales over small intervals of time. These places also can change more significantly over larger spans of time, as users and other agents make larger transformations. One of us went back to the same street five years later, and observed some significant changes, as can be seen in Fig. 4. Not only had some businesses closed and others opened, with some new signage, awnings and colours. New room-like spaces were also articulated, such as the two terraces above with new fences demarcating them, and offering a bit more privacy. The new business at the lower right demarcated a kind of stoop entry with the two planters at its entrance. Some demarcations also went away. The restaurant that formerly had outdoor seating removed most of it, perhaps because the weather wasn't suitable at that time. In any case, these were all small adaptive changes that added up to a bigger transformation of the entire streetscape.

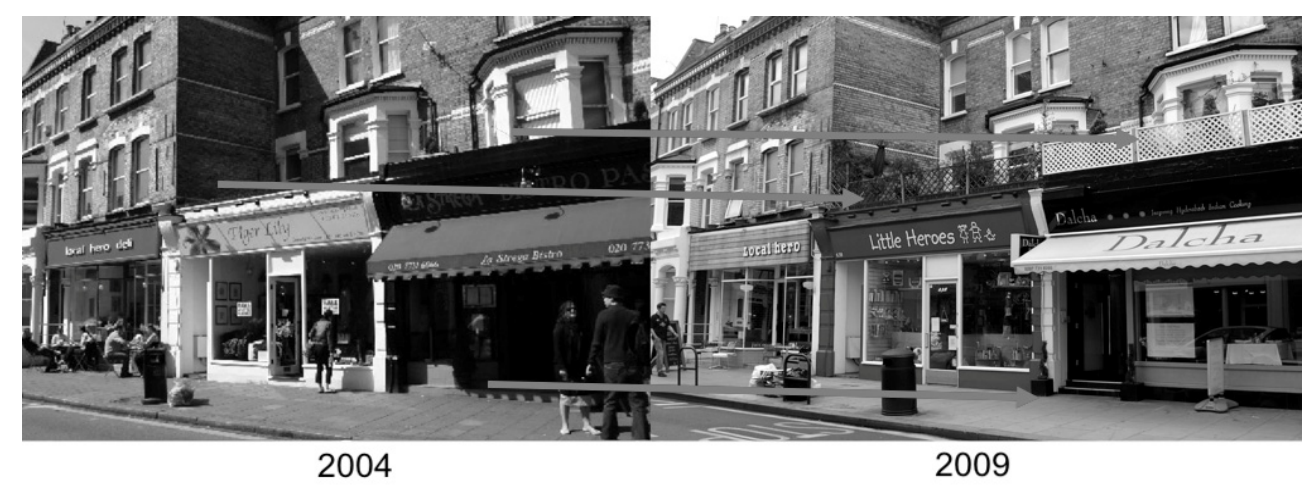

Figure 4: Transformations of the London streetscape and its spaces over just five years.

We see, then, that small adaptive changes of this kind can occur over five years - but what kinds of changes can occur from similar processes over a century, or several centuries? Fig. 5 is an example from the beautiful city of Venice, showing a section that began quite humbly as a series of rectangular plots (below left). Over an evolution of several centuries, that simple pattern had transformed into a complex configuration of interlocking spaces (right), with an even more complex three-dimensional structure (balconies, bridges, etc.) not shown in the plan. All these changes over several centuries have produced the remarkable urban structure that we all know and love today.

\section{THE EVOLUTION OF PUBLIC-PRIVATE SYSTEMS}

We can see many more examples of urban form that transforms according to such smallscale adaptive transformations, often as the result of simple agreements between buyers and sellers of relatively small plots of land. Ben Hamouche [4] documented the process of transformation of plots of land as owners sold sub-plots (Fig. 6(a)) and then subsequently made agreements with the buyers to create new public streets and lanes, so that they too could sell sub-plots, and/or erect viable commercial businesses on their land (Fig. 6(b)).

Hakim [5] has also described the way urban form is generated through the iterative application of form-specifying rules, such as those in Islamic building codes. For Hakim, this is an illustration of lessons from the sciences of complexity, which can describe cities as immense "complex adaptive systems" with properties of self-organization. That is, there need not be a central planning agency for many aspects of the city, including its public 


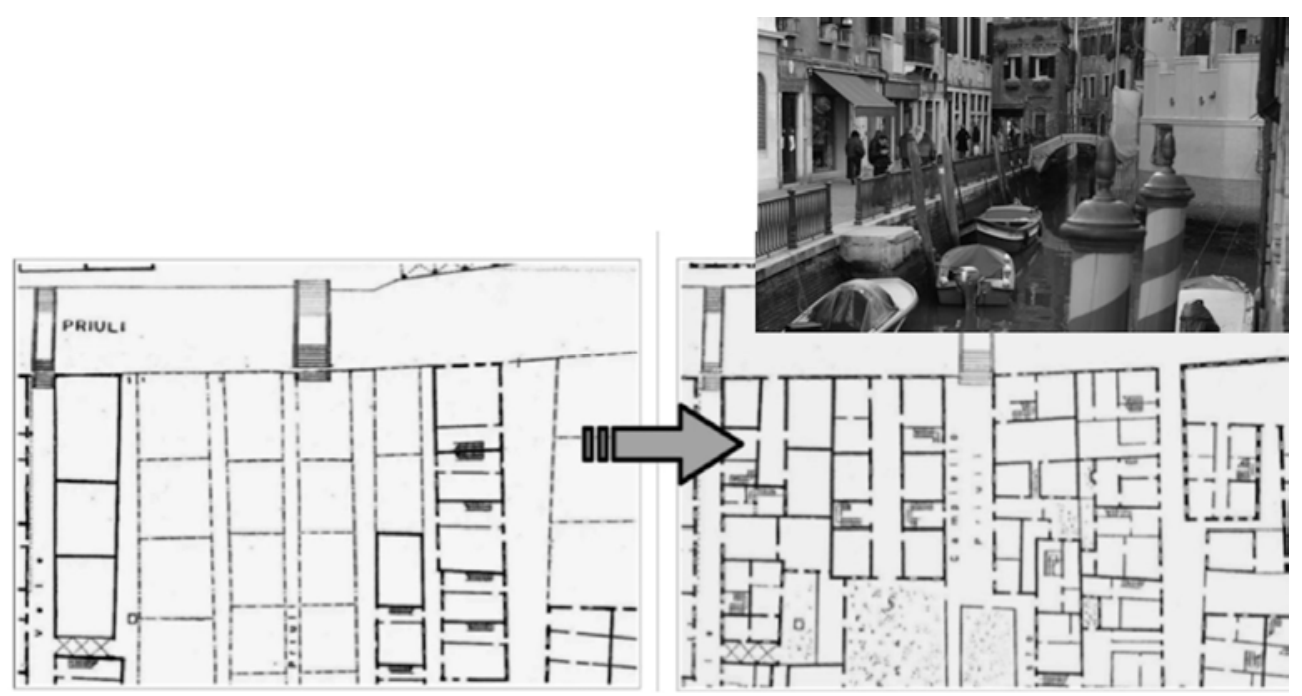

Figure 5: The remarkable transformation of a portion of Venice over time, from a simple set of rectangular plots to a highly evolved, complex set of "place networks". (Source: Muratori [3].)
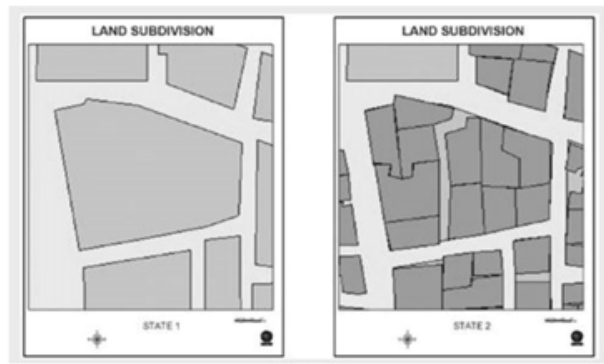

(a)
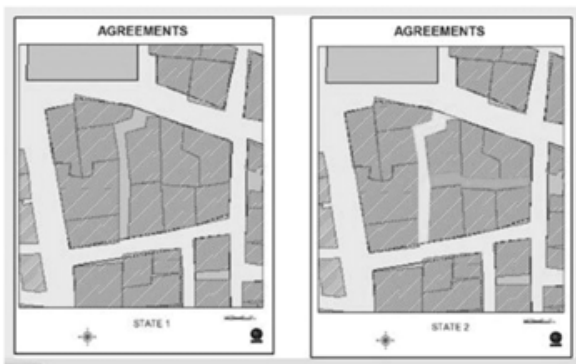

(b)

Figure 6: Evolution of an urban block. (Source: Ben Hamouche [4].)

spaces. Much of the form and character of these spaces can "emerge" from the local actions of agents - the citizens - and form surprisingly well-coordinated frameworks, through a step-wise adaptive process of self-organization.

This form of organization is sometimes referred to as "bottom-up", in that it comes from the decentralized actions of local agents. It is often contrasted with "top-down", or more centralized forms of planning and governance. Of course in reality there is usually a mix of the two, and moreover, there is a mix at a range of scales from the most bottom-up to the most top-down - and sometimes these organizational forces are overlapping and even conflicting.

For example, a city government may have rules for the use of public spaces, but the users of a park who are playing a game may have a separate set of rules for the movements allowed in the game. Tacit rules (like the one for not invading my picnic blanket) may form 
yet another overlapping layer of informal governance. Other rules might even be applied nationwide - for example, nation-wide rules for providing access to disabled people, imposed through mandatory standards of construction of ramps and pathways.

This "polycentric governance network" mirrors the polycentric network of public and private spaces in the city. Both are complex, partially emergent, and partly shaped "bottomup" by the people who occupy public space. In the case of public space, this was a point made by our Centre colleague Setha Low, describing the "social production of public space" [6].

\section{THE DEATH - AND LIFE - OF PUBLIC SPACE}

We may wonder, then, why public space is in decline in so many places, as Habitat III's Joan Clos pointed out. Again, it seems that we have failed to understand how cities actually work, and instead have left ourselves in the grip of a defective model - a point made by the urbanist Jane Jacobs in her landmark book The Death and Life of Great American Cities [7]. Jacobs argued that our model of cities was based on machine-like segregation and statistical sorting, rather than the "organized complexity" seen in biological systems - and also seen in the most vibrant cities of the past. Not understanding this, we have severed the complex tissues of the city's spaces, and its delicate self-organizing relationships between public and private realms.

The automobile is a part of the problem; but as Jacobs pointed out, the problem runs deeper, to the kind of city we build - as it happens in our case, around automobiles. When we enclose ourselves in the capsule of the car, transporting from the capsule of the home to the capsule of the workplace or other destinations, we sever this complex tissue, and change how the city works. We also change how the residents of the city move about and consume resources, in subtle but profound ways (Fig. 7).

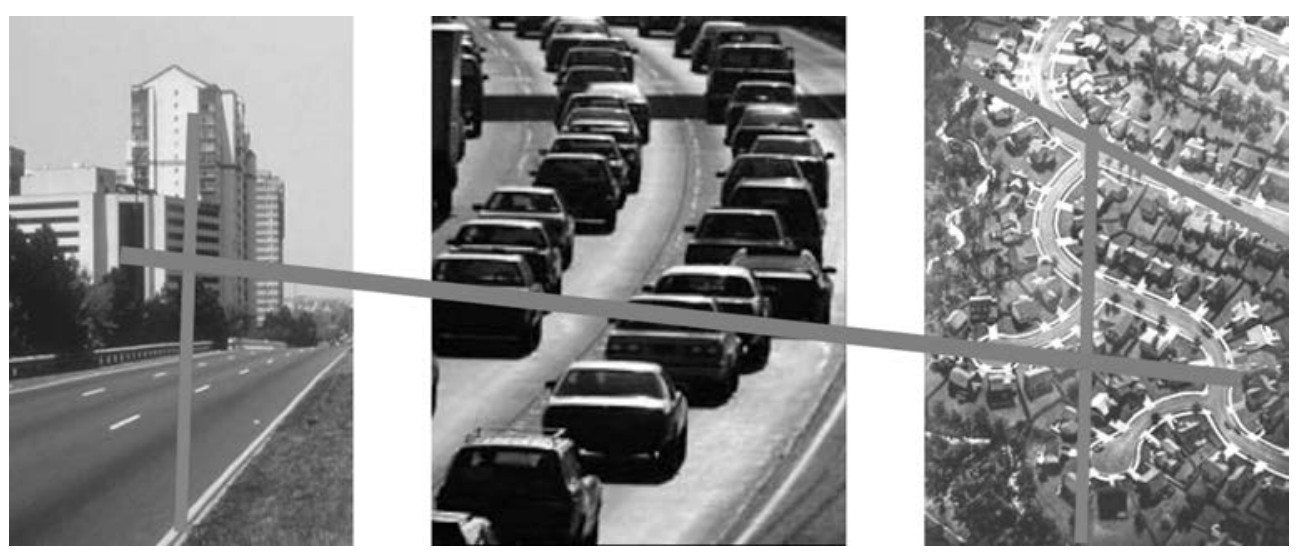

Figure 7: The capsule of the car, taking us from the capsule of home to the capsule of work - without encountering any public spaces.

It is possible to replace this city-wide system of public spaces with other kinds of networks - data, communications, high-speed transport and the like, forming a resourceintensive web of homes, offices and conference rooms. It is possible to operate an innovative and prosperous economy, as we can see from many sprawling cities with 
declining public spaces today. These artificial networks show many of the same signs of polycentrism and overlap that we see in the public space networks of great cities.

But something enormously important is lost in the bargain. Not only is this artificial network vastly more resource-intensive - and it may therefore be unsustainable over time but it excludes many of the people who most need access to the city's public space networks, and the resources to which they connect: the very young, the very old, the poor, and the infirm. As research by our colleagues at the KTH Centre and others has shown, populations with particularly acute needs, like migrant populations, depend upon the opportunities that a fine-grained mix of public and private spaces can offer, particularly along commercial or "main" streets.

This was a point made by the physicist-turned-urbanist Luis Bettencourt, who put it this way:

[This] view of cities in terms of social networks emphasizes the primary role of expanding connectivity per person and of social inclusion in order for cities to realize their full socioeconomic potential. In fact, cities that for a variety of reasons (violence, segregation, lack of adequate transportation) remain only incipiently connected will typically underperform economically compared to better mixing cities.... what these results emphasize is the need for social integration in huge metropolitan areas over their largest scales [8].

In the end, then, as Jacobs argued, a diverse, complex, well-connected public realm is good for everyone's bottom line. Innovation thrives on diversity, and on the propinquity, mixing, and serendipitous encounters that happen within public spaces, and the mobility within them that is facilitated by accessible transportation systems. When cities lose this diversity, Jacobs argued, they stagnate economically.

\section{CONCLUSION}

Thanks to the research that is now becoming available, we have an opportunity to draw out the lessons from the best cities of history, and apply them to a new generation of vibrant, complex, enriching public spaces. Central to this goal is the understanding and incorporation of good-quality public space networks, as the New Urban Agenda calls for. Using appropriate tools and strategies, we can make successful public space as places of peaceful co-presence, creative interaction, participation, and co-production. To achieve their maximum potential, we must build in their capacity to self-organise into a structure of territorial regions, combining private interiors with connective public edges. We need to develop and share the tools and strategies for that challenge as well - starting with the models of understanding of the dynamics of public space. This paper is only an outline of some of the requirements for that vital goal.

What is at stake is not only the economic function of our cities, or the efficiency of their resource use, or their equity and fairness - it is surely all that - but also the renaissance of their public life.

\section{ACKNOWLEDGEMENT}

The authors are grateful for research funding by the Ax:son Johnson Foundation.

\section{REFERENCES}

[1] Madanipour, A., Public and Private Spaces of the City, Routledge: London, 2013. 
[2] Clos, J., We have lost the science of building cities. Interview, The Guardian, 18 April 2016. www.theguardian.com/cities/2016/apr/18/lost-science-building-cities-joan-closun-habitat. Accessed on: 30 Jun. 2019.

[3] Muratori, S., Studi per una operante storia urbana di Venezia I. Palladio 3-4, Instituto Poligraphico dello Stato: Roma, 1959.

[4] Ben Hamouche, M., Complexity of urban fabric in traditional Muslim cities: Importing old wisdom to present cities. Urban Design International, 14(1), pp. 22-35, 2009.

[5] Hakim, B.S., The generative nature of Islamic rules for the built environment. International Journal of Architectural Research: ArchNet-IJAR, 4(1), pp. 208-212, 2010.

[6] Low, S.M., Spatializing culture: The social production and social construction of public space in Costa Rica. American Ethnologist, 23(4), pp. 861-879, 1996.

[7] Jacobs, J., The Death and Life of Great American Cities, Random House: New York, 1961.

[8] Bettencourt, L.M.A., The kind of problem a city is. Santa Fe Working Paper 2013-03008. Santa Fe Institute, 2013. https://sfi-edu.s3.amazonaws.com/sfi-edu/production/ uploads/sfi-com/dev/uploads/filer/fa/f6/faf61418-fc4f-42d5-8c28-df1 197a39018/1303-008.pdf. Accessed on: 30 Jun. 2019. 